\title{
Assessment of Durability and Long Term Performance of High Density Polyethylene Drainboards in the Gotthard Railway Tunnels
}

\author{
Marcus Jablonka \\ Cosella-Dörken Products, Inc., Ontario LOR 1B4, Canada
}

\begin{abstract}
Drainage layers provide permanent relief of hydrostatic water pressure, while the waterproof liner prevents any ingress of water into the tunnel. The durability and aging resistance of drainage membranes are of primary concern. This paper describes advantages and concerns related to the usage of, and the design with, polymeric drainboards in tunnel construction. Common degradation mechanisms associated with HDPE (high density polyethylene) sheets are described. The stringent requirements for the Gotthard Alpine Railway Tunnel through the Swiss Alps, e.g., high ambient temperatures of up to $45^{\circ} \mathrm{C}$ and an expected service life of up to 100 years require outstanding aging resistance of polymeric drainage materials. The paper describes the methods deployed to investigate the long-term performance of HDPE drainboards, focusing on aging mechanisms. Details associated with the test procedures developed to reflect the specific properties of drainboards, as well as the results obtained, are presented. A summary table shows recommended product specifications needed to confine the aging properties of drainboards and to design a system performing adequately during the entire lifetime of the structure.
\end{abstract}

Key words: Durability, long term performance, HDPE, drainboards, tunnel.

\section{Introduction}

Drainboards have been frequently employed in tunnel lining applications, both in cut-and-cover projects and in bored tunnels. The function of the drainage layer is to provide permanent relief of hydrostatic water pressure, while the waterproof liner prevents any ingress of water into the tunnel. Such systems are subjected to high mechanical, physical, chemical and sometimes biological operational demands, both during the installation period as well as later in-situ during the service life. In order to provide adequate performance, drainage products must maintain their full integrity over the entire design life of the structure. While product specifications often avoid any reference to durability and long-term performance properties, it is clear that aging processes affect these polymeric materials. Hence, the durability

Corresponding author: Marcus Jablonka, Dipl. Ing., Dipl. Wirt. Ing., research field: durability of polymeric construction products. E-mail: mjablonka@cosella-dorken.com. and aging resistance of drainage membranes, like any polymeric products, is of primary concern.

Damage to underground building structures due to exposure to water ranks high in damage statistics of buildings [1]. Identifying expected water exposure conditions is, therefore, an important step for proper planning of a waterproofing and drainage system. An effective drainage layer greatly improves and warrants the reliability of the waterproofing layer by relieving hydrostatic pressure caused by dammed-up seepage water. Furthermore, a drainboard can provide effective protection for a waterproofing liner against potential damage from mechanical impact and consequential moisture intrusion.

Polymer based materials are commonly used to manufacture drainboards, providing inherent advantages, such as, low weight, ease of application, etc.. Sometimes, such materials are even used where products with long expected service lifetimes are required. 
This paper reflects on advantages of using Polyethylene based drainboards and on their performance criteria. Since organic materials are affected by physical and chemical ageing processes, long-term durability and possible concerns associated with the deployment of such polymeric products are also discussed. Degradation mechanisms of HDPE (high density polyethylene) membranes are described and the requirements for long-term properties for drainage materials for new railway tunnels through the Swiss Alps with expected service lifetime requirements of up to 100 years [2] are discussed.

Test procedures developed to reflect the specific properties of drainboards are presented, as well as the results obtained. A summary table shows recommended product specifications needed to confine the aging properties of dainboards and to design a system performing adequately throughout the entire lifetime of the structure.

\subsection{Advantages of Polymeric Drainboards}

Drainboards, generally comprised of a semi-rigid polymeric sheet with a 3-dimensional dimple structure, make an excellent drain on sub-grade structures [3]. Such products are commonly used to protect structures against moisture, to control ground water, and to reduce or eliminate hydrostatic pressure. Drainboards are also instrumental in tunnel lining applications to intercept artesian, fissure and seepage water.

Gravity forces can cause hydrostatic pressure build-up of water on sub-grade structures. The main objective of drainboards is to reduce or eliminate hydrostatic pressure against below grade structures by providing an effective drainage layer, and to prevent infiltration of water into the construction. A typical high-density polyethylene based drainboard is shown in Fig. 1.

In tunnel lining applications, the drainage path for the water is provided by the air gap between the studded polymer core and the shotcrete surface. Fig. 2 illustrates how seepage water passes through the shotcrete layer and is safely drained to the footer drain.

\subsection{Performance Criteria for Drainboards}

For a drainboard to function effectively throughout the lifetime of the structure, key performance criteria must be evaluated, also with respect to long-term durability. They can be categorized into mechanical properties, hydraulic properties and durability. While drainboards are generally available with or without a geotextile laminated to the drainage core material, it should be noted that this paper only reflects on drainboard types without geotextiles. In this type of application, a geotextile is not required since the shotcrete acts as a filter layer.

Mechanical properties comprise the compression behavior of a drainboard, typically described as stress over strain. This material characteristic is important since the 3-dimensional membrane will be exposed to pressure, and its drainage capability is dependent on its

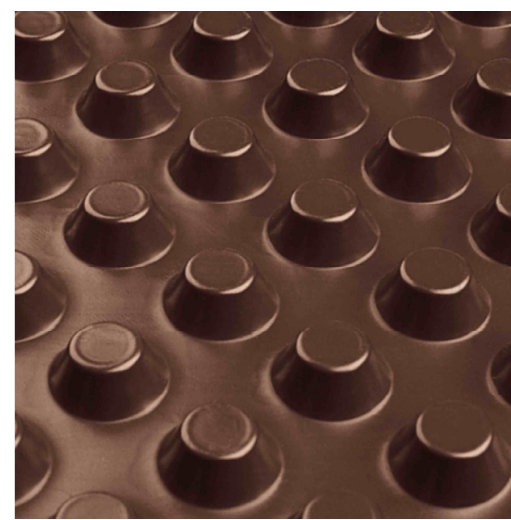

(a) Top view

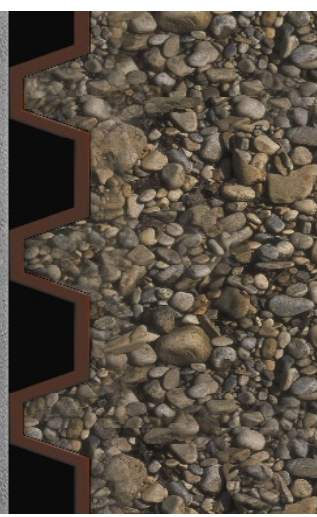

(b) Side view (in situ)

Fig. 1 Typical HDPE drainboard. 


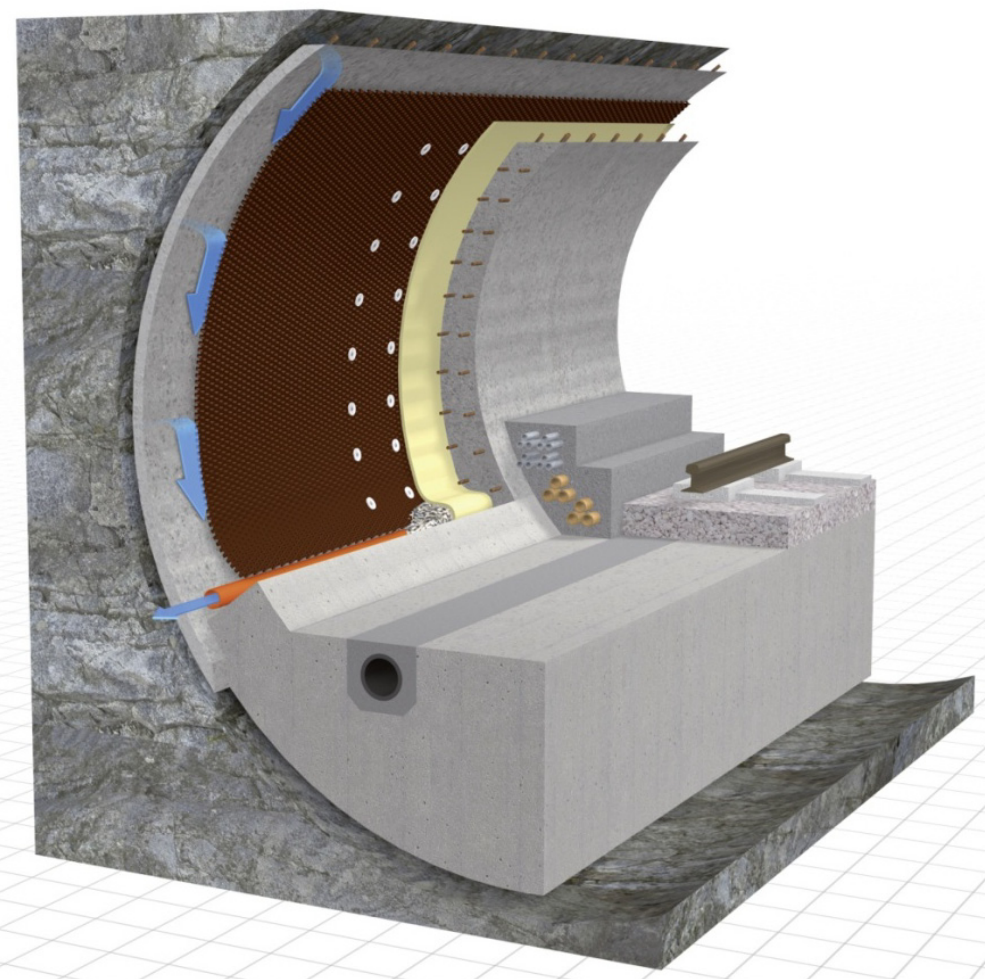

Fig. 2 Drainboard in tunnel lining application.

compression resistance. An appropriate test method for determining the short-term compression behavior of a drainboard is ASTM D6364. While this test standard can give an indication of the momentary compression behavior of the material, it cannot, by itself, characterize the long-term compression behavior of the product.

Other important mechanical properties of drainboards are breaking force and elongation, measured according to ASTM D5035. In addition, the static and dynamic puncture resistance of these membranes is important. Dynamic puncture resistance reflects the product's ability to sustain the shock induced by the fall or impact of objects as may occur during installation. Static puncture reflects the ability of the product to sustain a local pressure. Appropriate test standards are CGSB 37-GP-56M and CGSB 37-GP-52M.

Furthermore, hydraulic transmissivity and in-plane flow rate are important performance characteristics of a drainboard. These characteristics can be determined and described as per ASTM D4716.
In order to characterize the long-term durability of drainboards, a number of standard test methods can be employed. For characterization of aging and oxidation, an oven-aging test as per ASTM D5721 and an OIT (oxidative induction time) test as per ASTM D3895 are suitable in combination with compression behavior testing at different intervals of aging.

Another degradation mechanism with relevance for HDPE drainboards is environmental stress-cracking. Generally, suitable test methods to determine the ESCR (environmental stress-cracking resistance) are ASTM D1693 in most of the plastics industry, ASTM D5397 in the HDPE geomembrane industry, or ASTM F2136 in the HDPE pipe industry. However, the particular structure of drainboards (e.g., sheet thickness, presence of recycled polyethylene in co-extruded configurations) may not allow the use of these common tests. A test method referenced as Sageos GD001 (stress cracking resistance of dimpled sheets) as described by Jablonka and Blond [4], characterizes the ESCR of polyethylene-based drainboards. 


\subsection{Durability of HDPE Drainboards}

While polymers are being utilized in virtually every area of our life, the volume of polymers used in the above-mentioned applications represents only a fraction of the entire polymer market worldwide. The use of high density polyethylene in drainboards differs from many other applications since these membranes are intended to fulfill their function over long time periods. While some HDPE articles are made for short time periods only, drainboards are expected to fulfill their function for the lifetime of the structure - typically in the range of 50 years or more.

Durability concerns, therefore, need to be understood and evaluated. Most situations involving the expertise of a geotechnical engineer are dealt with under the aspect of ground water conditions, seepage, settlement, pressures, etc.. Typically, the short-term properties of materials are being evaluated without giving much consideration to their durability and potential degradation factors. Important to the durability of drainboards is their raw material formulation, the imposed in-service conditions, as well as the environmental conditions to which they will be exposed between manufacturing and the actual service life.

The material formulation deserves special attention when recycled content is used in such membranes; especially if the membranes are made of $100 \%$ recycled HDPE. Since the use of recycled content in drainboards may potentially compromise their long-term durability, the intensity of the negative impact must be evaluated and understood in order to ensure that the key performance characteristics are maintained throughout the functional service life of these products.

\section{Degradation Mechanisms Relevant to HDPE Drainboards}

Aging and degradation of polymers essentially take place at the molecular level. Polymers are materials composed of large molecules of very high molecular weight. The cohesive forces of a polymer, which greatly affect the physical and chemical degradation mechanisms that can take place, are determined by the chemical composition of the polymer.

The molecular structure of polyethylene is shown in Fig. 3.

The characteristics of the polymer depend on intermolecular forces and are greatly influenced by the chain structure (i.e., chain length, linearity, branching, cross-linking, etc.), morphology (i.e., crystallinity), molecular weight distribution, irregularities (i.e., impurities), additives (i.e., color pigments, antioxidants, UV (ultraviolet) light stabilizers, flame retardants, antistatic agents, etc.), as well as by the manufacturing process itself, during which the polymer is exposed to thermal and shear stresses initiating degradation mechanisms. Process conditions will also determine the effectiveness of mixing additives and stabilizers into the polymer, which can influence the morphology of the end product and the degree of stabilization against environmental factors like heat, UV, oxygen, etc..

Essential aging and degradation mechanisms of polymers commonly used in geosynthetics, have been described in depth by Kay et al. [5]. HDPE is generally very resilient against environmental factors. Due to a low degree of branching, polyethylene has strong intermolecular forces and tensile strength. Being non-polar, it provides a very high resistance to chemicals. The permeability of polyethylene to liquids and gases is very low. It is also very resilient to alkaline and acidic agents, as well as salt solutions. Polyethylene copolymers generally provide good low-temperature flexibility and increased environmental stress cracking resistance. Hence HDPE

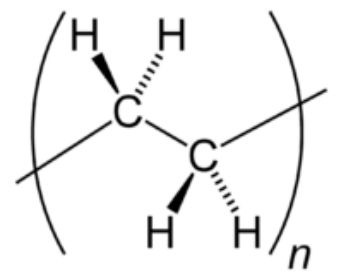

Fig. 3 Molecular structure of polyethylene. 
(copolymer) seems to be the ideal polymer to be used for drainboards.

However, during their functional service life, drainboards are exposed to several relevant degradation mechanisms. These aging mechanisms can, under certain circumstances, influence their properties and even reduce their durability and lifetime expectancy. Hence, the characteristics of the material used as well as the actual exposure conditions must be considered in order to evaluate the potential implication of these degradation mechanisms for the final product and its functional service life.

One of the most relevant degradation mechanisms of HDPE is oxidation, which can occur in form of thermo-oxidation, photo-oxidation, and chemical oxidation. The long-term durability and performance of polyethylene membranes can be ensured through adequate stabilization with antioxidants and UV stabilizers.

In the presence of sensitizing agents HDPE can become sensitive to environmental stress cracking, which — next to oxidation — is the most relevant degradation mechanism of this polymer. ASTM D883 explains stress cracking as “an external or internal crack in a plastic caused by tensile stresses less than its short-term mechanical strength.” This typically describes brittle cracking with little or no ductile drawing from the adjacent failure surfaces of the polymeric material. The occurrence of environmental stress cracking of stressed samples is linked to the presence of surface-active wetting agents such as alcohols and surfactants. The surface-active wetting agents do not chemically attack the polymer, nor do they produce any effect other than microscopically brittle-appearing fractures. The fractures initiate at microscopic imperfections in the material, and propagate through the crystalline regions of the polymer structure. In the absence of such surface-active wetting agents, these fractures would not occur in any reasonable time period under the same stress conditions.
A polymers' ability to resist environmental stress cracking is generally known as ESCR. Different polymers exhibit varying levels of ESCR. It is important to know that the stress cracking susceptibility between different types of PE can be very different [6]. Some grades of HDPE have very good ESCR, while other grades only show a marginal resilience. The principle variables that affect the ESCR in HDPE include the crystallinity, molecular weight (ESCR improves as molecular weight increases), the molecular weight distribution (generally a narrow molecular weight distribution shows poorer ESCR values than a broader distribution), branch length, and lamellar orientation [7]. Naturally the ESCR testing conditions (i.e., reagent concentration, testing temperature and applied stress) also have a major influence on the ESCR that the tested sample will exhibit. Recycled content is also known to affect the ESCR of polymers. Historically and practically, recycled materials do not perform as well as virgin polymers when subjected to environmental stress-cracking.

The effects of, as well as the resistance to environmental stress cracking of polyethylene based drainboards and a suitable test procedure have been discussed in depth by Jablonka and Blond [4]; the differences in environmental stress crack resistance of polyolefin based dimple sheets can be very significant as shown in Fig. 4.

Perhaps the most important factors governing the degradation rate of polymeric drainboards are the ambient $\mathrm{pH}$ value [8] and the ambient temperature. As quantitatively described by the Arrhenius equation, the rate of degradation increases with an increase in ambient temperature.

\section{Long-Term Performance of HDPE Drainboards in the Gotthard AlpTransit Railway Tunnel}

\subsection{Durability Requirements}

As part of a new railway connection from the north 


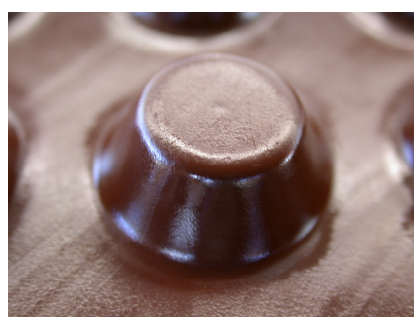

(a) No failure

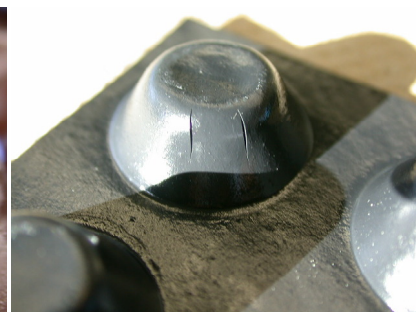

(b) Cracking

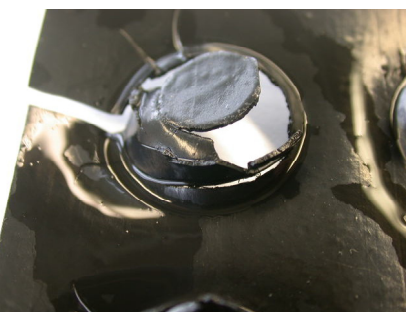

(c) Severe cracking

Fig. 4 Environmental stress cracking on three different drainboard specimens after submersion in alkaline water at elevated temperature and lateral load.

to the south in Switzerland, the Gotthard base tunnel is being built as a double-shell tunnel. With a total length of $56.8 \mathrm{~km}$, the Gotthard tunnel is the longest tunnel in the world. Fig. 5 shows a combination of a waterproofing system and a drainage layer between the shotcrete outer shell and the concrete inner shell. This design concept continuously drains seepage water away in order to protect the concrete shell against hydrostatic pressure, and to locally transfer high loads onto the concrete support structure.

At the base, where the mountain cover is up to $7,500 \mathrm{ft}$ high, geothermal effects can generate rock temperatures of up to $45{ }^{\circ} \mathrm{C}$. Hence, the seepage water can also reach temperatures of up to $45^{\circ} \mathrm{C}$. The water is mostly alkaline, but may also be acidic in some areas.

The expected service lifetime for this tunnel is 100 years, with no major repairs being necessary for at least 50 years. There are currently no existing test standards with suitable criteria for such high loads and requirements, and the drainage materials available previously had not been designed for or tested under comparable conditions. Hence, a comprehensive product evaluation had to be performed.

\subsection{Durability Testing}

A number of different waterproofing systems and drainboards were tested in regards to their ageing resistance in a 24 months program. The test program has been described in depth by Flüeler and Böhni [2].

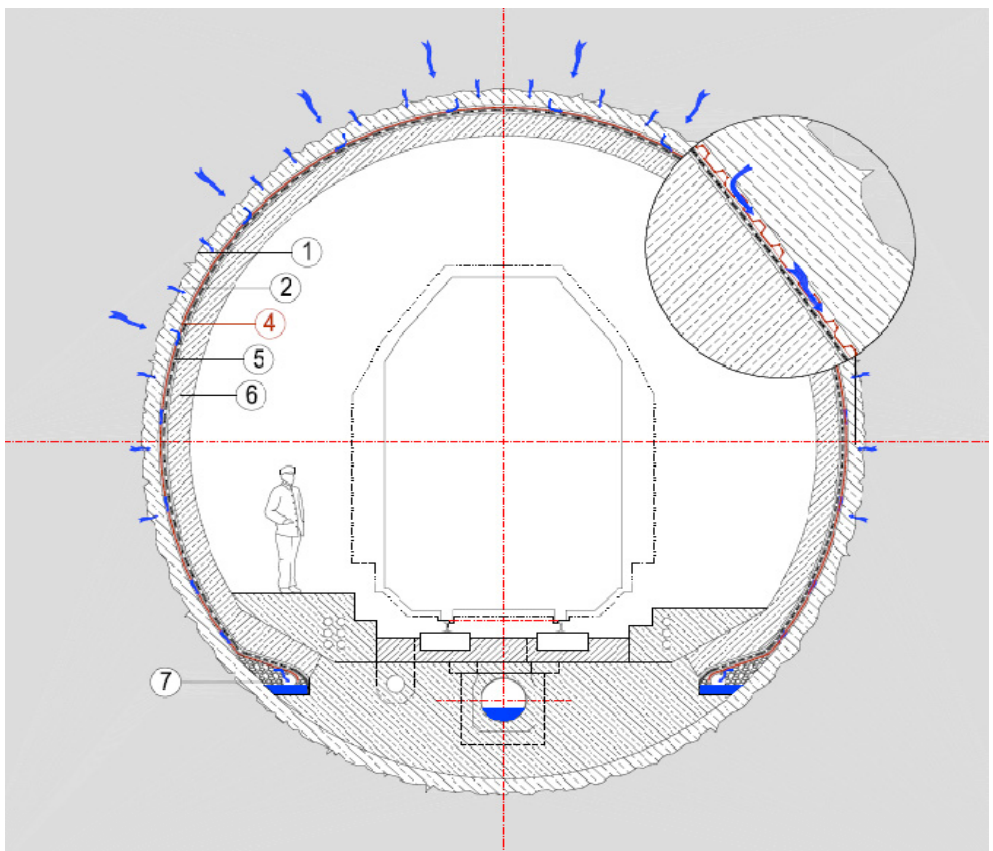

Fig. 5 Detail of tunnel wall showing rock (1), shotcrete surface (2), drainboard (4), waterproofing (5), concrete liner (6) and drainage pipe (7). 
The drainage products that were submitted for testing were made from polyethylene, polypropylene, polyamide and polyester. These products included dimpled sheets (drainboards), nets, randomly oriented mats and non-woven geotextiles. This paper focuses on polyethylene-based drainboards only.

The test program comprised existing test methods, that were augmented by additional procedures, e.g., aging resistance in oxygen-enriched water at elevated temperatures, compression creep tests between rough surfaces, tests under combined lateral loads and horizontal shear, as well as installation tests including the construction of the concrete support shell.

\subsection{Aging}

During the ageing part of the material evaluation the drainboard specimens were exposed to a number of different conditions for a period of 24 months:

- Water circulated at $23{ }^{\circ} \mathrm{C}$;

- Water circulated at $45^{\circ} \mathrm{C}$;

- Water circulated at $70^{\circ} \mathrm{C}$;

- Alkaline water (saturated calcium-hydroxide solution) circulated at $50^{\circ} \mathrm{C}$;

- Acidic water $(0.5 \%$ solution of sulphuric acid $)$ circulated at $50{ }^{\circ} \mathrm{C}$;

- Oxygen-enriched water circulated at $70{ }^{\circ} \mathrm{C}$ and 3 bar pressure;

- Environment with aerobic and anaerobic microorganisms.

Fig. 6 shows the schematic of a pressure vessel for ageing of specimens in oxygen-enriched water at elevated temperature and pressure.

For five times during the test period, the specimens were tested for visual appearance, mass changes, in-plane water transmissivity and mechanical properties. In addition, thermoanalytical tests were applied after 3, 6, 12 and 24 months to sufficiently characterize the aging behavior of the products. Furthermore the performance of the specimens under compression creep load was evaluated.

\subsection{Results}

The drainage materials generally reacted to acidic and alkaline exposure. Some polyamide and polyester based products decomposed in acidic water and embrittled in hot water $\left(70^{\circ} \mathrm{C}\right)$ within six months. While the polyethylene based drainboard specimens with a weight of $1,200 \mathrm{~g} / \mathrm{m}^{2}$ and a maximum compressive strength of $950 \mathrm{kN} / \mathrm{m}^{2}$, specifically formulated and stabilized to withstand the harsh environment, were relatively unaffected by these conditions, they did show noticeable effects of ageing in hot environments

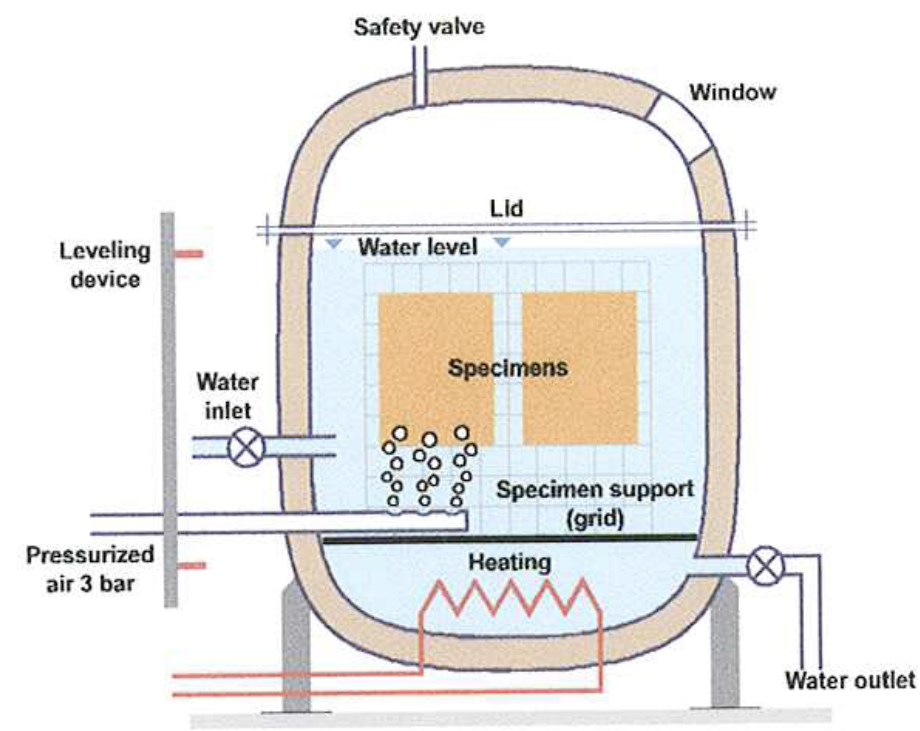

Fig. 6 Schematic of pressure vessel for ageing in oxygen-enriched water at elevated temperature and pressure. 
when submitted to compression creep load. However, in spite of large deformations of drainboards under such conditions, they still proved to be fairly well suited as the water inlet pressure during in-plane water transmissivity tests under lateral loads remained consistently low (Fig. 7).

Minor visual changes such as loss of glance were detected on polyethylene based drainboards after 24 months exposure to all conditions. Only small changes were detected after exposure of the specimens to micro-organisms under aerobic or anaerobic soil conditions.

The mass loss of $0.8 \%$ for polyethylene based drainboards after 24 months of ageing in water at $23{ }^{\circ} \mathrm{C}$ was very low. After 24 months exposure to $70{ }^{\circ} \mathrm{C}$ water, the polyethylene based drainboard yielded a modest mass increase. After exposure to alkaline or acidic conditions, the specimens also showed modest mass changes.

The in-plane water transmissivity values of the drainboard specimens, measured at a lateral load of $200 \mathrm{kN} / \mathrm{m}^{2}$ after exposure, were generally not different from those measured in the as-received state.

All exposure conditions, as shown in Table 1 [9], could be met with a specially formulated polyethylene based drainboard.

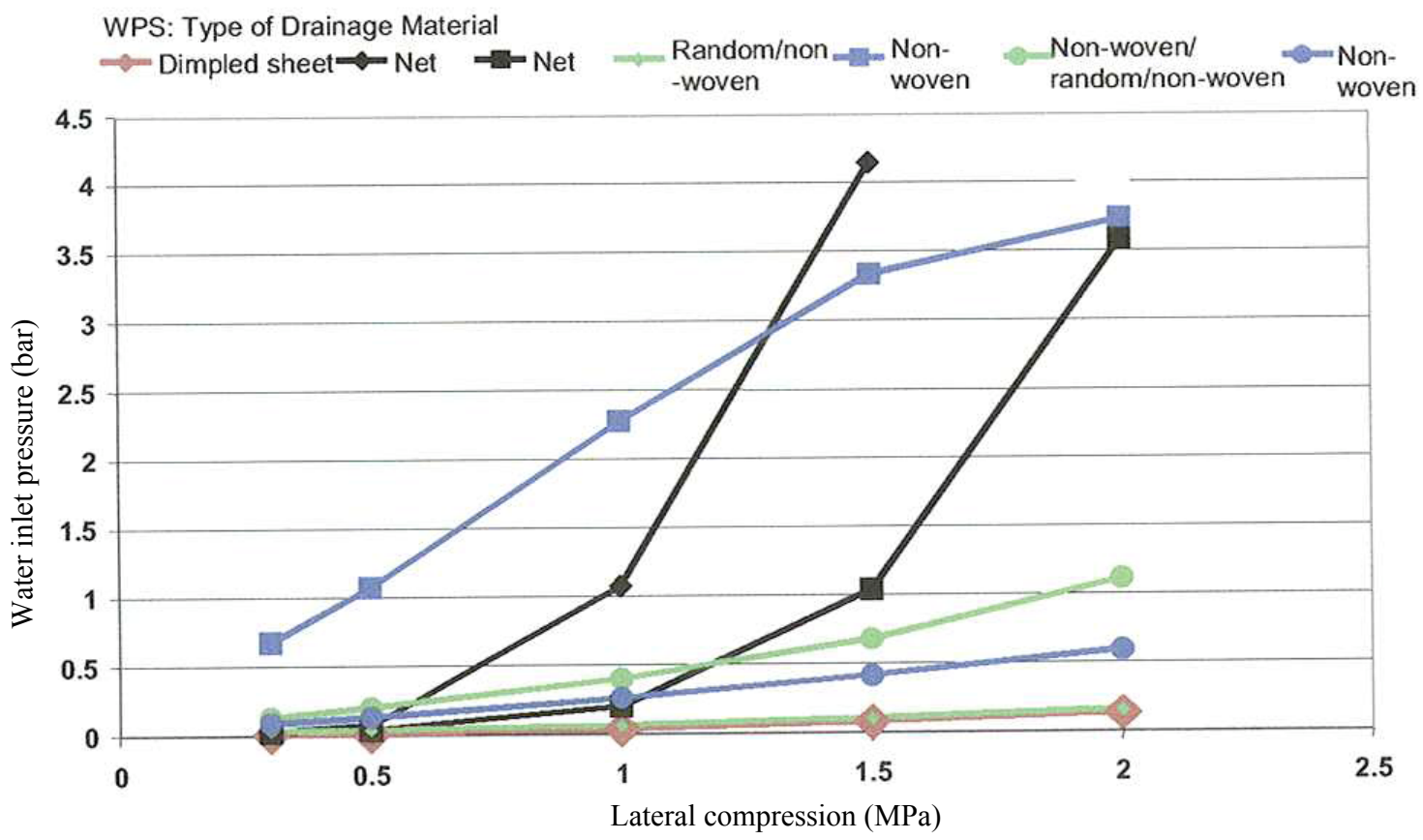

Fig. 7 Inlet pressure of drainage water versus lateral compression load.

Table 1 Exposure conditions, criteria and requirements after 24 months aging for polymeric drainboards.

\begin{tabular}{llll}
\hline Conditions & Change in mass & $\begin{array}{l}\text { Change in mechanical } \\
\text { strength }\end{array}$ & Transmissivity \\
\hline Water at $23^{\circ} \mathrm{C}$ & $\leq 4 \%$ & $\leq-20 \%$ & $>10^{-4}\left(\mathrm{~m}^{2} / \mathrm{s}\right)$ \\
Water at $45{ }^{\circ} \mathrm{C}$ & $\leq 5 \%$ & $\leq-30 \%$ & $>10^{-4}\left(\mathrm{~m}^{2} / \mathrm{s}\right)$ \\
Water at $70^{\circ} \mathrm{C}$ & $\leq 7 \%$ & $\leq-50 \%$ & $>10^{-4}\left(\mathrm{~m}^{2} / \mathrm{s}\right)$ \\
$0.5 \%$ sulphuric acid at $50{ }^{\circ} \mathrm{C}$ & $\leq 7 \%$ & $\leq-50 \%$ & $>10^{-4}\left(\mathrm{~m}^{2} / \mathrm{s}\right)$ \\
Aqueous saturated calcium-hydroxide solution & $\leq 7 \%$ & $\leq-50 \%$ & $>10^{-4}\left(\mathrm{~m}^{2} / \mathrm{s}\right)$ \\
Aerobic micro-organisms in soil at $29{ }^{\circ} \mathrm{C}, 98 \%$ relative humidity & $\leq 7 \%$ & No requirements & No requirements \\
Anaerobic micro-organisms in soil at $29^{\circ} \mathrm{C}, 98 \%$ relative humidity & $\leq 7 \%$ & No requirements & No requirements \\
\hline
\end{tabular}




\section{Conclusions}

Polymer based drainboards are affected by physical and chemical aging processes. Degradation mechanisms and aging processes of HDPE membranes, as well as requirements for long-term properties for drainage materials for the Swiss Alp Transit tunnels with expected service lifetime requirements of up to 100 years, have been discussed in this paper. Test procedures that have been developed to characterize the aging behavior of such products have been presented.

The results from the extensive test program showed that standard waterproofing/drainage systems would be unable to fulfill the requirements for the Alp Transit Base Tunnels. However, refined systems were able to prove their suitability to fulfill the stringent requirements.

A specially formulated polyethylene based drainboard underwent a stringent test procedure. Drainboard samples were aged over a 24-month period. During the aging period the specimens were submerged in acidic and alkaline solutions at $50{ }^{\circ} \mathrm{C}$ and in oxygen-enriched water at $70{ }^{\circ} \mathrm{C}$ and then tested again. All required product specifications needed to confine the ageing properties of dainboards, could be met.

\section{References}

[1] R. Abel, G. Dahmen, R. Lamers, R. Oswald, V. Schnapauff, K. Wilmes, Core areas of structural damage for restoration and maintenance measures, Aachener Institutfür Bauschadensforschung und angewandte, Bauphysik, 1991. (in German)

[2] P. Flüeler, H. Böhni, The sealing of deep-seated swiss alpine railway tunnels-New evaluation procedure for waterproofing systems, in: The 11th International Techtextil-Symposium Für Technische Textilien, Vliesstoffe und textilarmierte Werkstoffe, Frankfurt a.M., Apr. 23-26, 2001, p. 8.

[3] R.M. Koerner, Designing with Geosynthetics, 4th ed., Prentice-Hall, Inc., Upper Saddle River, USA, 1997.

[4] M. Jablonka, E. Blond, Long Term Performance Requirements for HDPE Drainboards, Geosynthetics 2009, Salt Lake City, USA, 2009.

[5] D. Kay, E. Blond, J. Mlynarek, Geosynthetics durability: A polymer chemistry issue, in: The 57th Canadian Geotechnical Conference, Quebec, 2004.

[6] Y.G. Hsuan, Data base of field incidents used to establish HDPE geomembrane stress crack resistance specification, Geotextiles and Geomembranes 18 (2000) 1-22.

[7] A. Lustiger, Understanding Environmental Stress Cracking in Polyethylene, Medical Plastics and Biomaterials Magazine, July, 1996.

[8] S. Corbet, J. King, Geotextiles in Filtration and Drainage, Thomas Telford Services, London, Great Britain, 1993.

[9] E. Basler, Approval test for waterproofing systems for the base tunnels of AlptTransit Gotthard and Lötschberg, Requirements, Oct. 1, 1998. (in German) 